\title{
Theoretical and ethical issues using Heidegger's hermeneutics in a research project with children living with physical, intellectual or social disabilities
}

\author{
Marie-Eve Laforest ${ }^{* 1}$, Pawel J. Krol ${ }^{2}$, Nancy Leblanc ${ }^{2}$ \\ ${ }^{1}$ School of Nursing, University of Moncton, Moncton, Canada \\ ${ }^{2}$ Faculty of Nursing, Laval University, Quebec City, Quebec, Canada
}

Received: April 12, 2017

DOI: $10.5430 /$ jnep.v7n10p46

\author{
Accepted: April 26, 2017 \\ Online Published: May 10, 2017 \\ URL: https://doi.org/10.5430/jnep.v7n10p46
}

\begin{abstract}
Hermeneutic phenomenology can contribute to the understanding of the lived experience of various health phenomenon of nursing. Although hermeneutic phenomenology is gaining importance in nursing research, it remains important to discuss the theoretical and ethical issues that may be encountered when using such methodology with children living with disabilities. A critical discussion on the use of Heidegger's hermeneutics when studying the lived experience of children living with disabilities, will help us gain insight on the issues that we may come across as researchers. This article begins with an insightful overview of the core concept of Heidegger Hermeneutic Phenomenology (HHP) followed by a discussion on theoretical and ethical issues that may arise when doing research with children living with disabilities - the topic as example. In light of this discussion, we suggest some innovator implications for nursing practices and nursing research.
\end{abstract}

Key Words: Heidegger Hermeneutic Phenomenology (HHP), Epistemology, Concepts, Nursing research, Children living with disabilities, Theoretical issues, Ethical issues

\section{INTRODUCTION}

Hermeneutic phenomenology, as a qualitative methodology, is gaining significance in nursing research due to the deep insight gleaned from this method within human experience. ${ }^{[1]}$ Hermeneutic phenomenology research can contribute to the understanding of different health phenomenon of interest for the nursing discipline. As we are getting ready to undertake a hermeneutic phenomenology research project with children living with physical, intellectual or social disabilities, we are faced with an important question: What are the theoretical and ethical issues - in the nursing discipline domain - of hermeneutics when studying children living with disabili- ties? Thus, this paper addresses the positive and negative outcomes of using hermeneutic when studying this phenomenon. In doing so, we will develop our arguments drawing from Heidegger's hermeneutic philosophy and authors who investigated this method/philosophy. We will then make explicit what can be gained and lost using hermeneutics by referring to the heideggerian concepts of Dasein, the fore-structure and situatedness of the researchers, the meaning and theory of truth, the notion of language as well as the existentials of Being-in-the-world. ${ }^{[2-4]}$ To conclude, we will argue the implications of Heidegger's hermeneutics for nursing practice and nursing research. Thus, the purpose of this paper is

\footnotetext{
${ }^{*}$ Correspondence: Marie-Eve Laforest; Email: marie-eve.laforest.1@ulaval.ca; Address: School of Nursing, University of Moncton, Moncton,
} Canada. 
to discuss the emergent theoretical and ethical issues when using Heidegger's hermeneutics in research, in this case with children living with disabilities.

\section{OUR RESEARCH PROJECT}

Having worked with children living with physical, intellectual or social disabilities in a community setting, we observed that the actions of nurses have different effects on the child's development and well-being. We are also aware that some nurse interventions are more beneficial than others. Based on our experiences of working with these children, it is our desire to contribute authentically to their development and well-being. We then ask ourselves how we, as nurses, can contribute to their well-being. After all, the nursing discipline is in part concerned with maintaining and restoring health and well-being. ${ }^{[5]}$ Therefore, we consider important to undertake a qualitative study that allows us to gain a deeper and more authentic understanding of the meaning of wellbeing in children living with disabilities and how the actions of nurses can contribute to their well-being. So, we judged it appropriate to use hermeneutic phenomenology to theorize about the well-being of children with disabilities and the actions of nurses.

We believe that the experience of well-being for the child living with disabilities is subjective and experiential. Each child has a different way of experiencing health and well-being. Therefore, this vision of the child living with disabilities orientates us to consider a qualitative phenomenological research design for this study.

\section{Heidegger Hermeneutic NOMENOLOGY (HHP)}

In this section we explain some of the core concepts used in heideggerian hermeneutic phenomenology, which is, at first glance, somehow complex. Our aim here is to provide a comprehensive explanation in order to contribute to their relevance to nursing research, philosophy and the practice of nursing care. So, before attempting any HHP inquiry, we suggest that the researcher needs to situate himself within Heidegger's philosophy and its core concepts. To do so, we will mainly draw from the writing of Michael Gelvin ${ }^{[2]}$ and John Idhe ${ }^{[3]}$ - renowned commentators of Heidegger's central work Being and Time, as well as the awarded work of Lamarre $^{[4]}$ - who used HHP in her educational research.

HHP can be used to provide deeper understanding of the meaning of being a person as well as what it means to be in the world; it aims to interpret and construct an understanding of the human existence in his everyday world. ${ }^{[3,6,7]}$ In order to reach an understanding of what it means to be in the world, the researchers need to consider Heidegger's ontological concept of the Being-in-the-World. Palmer ${ }^{[6]}$ explains that the ontological quest must first move toward the interpretation of the person experiencing the phenomenon that authentically reveals itself. This quest needs to create epistemic opportunities to allow some hidden structures or information of the Being-in-the-World to be sizeable and interpretable. ${ }^{[6]}$ Watts $^{[8]}$ explains that unlike other Western or Continental philosophers, Heidegger was primarily concerned with understanding of the «meaning» of Being - as ethics - rather than just knowing the Being - as pure ontology. Specifically, each person is concerned with the way he feels, understands his life events and exists. Here, Heidegger philosophizes about the person's existence in the sense of one being «aware» that one is alive, rather than simply «being» alive. ${ }^{[2]}$ And, to do so, we need to consider heideggerian concept of Being-in-the-World. ${ }^{[9]}$

The concept of Being-in-the-World delineated by Heidegger can be understood as a twofold structure that comprises the concept the Being-in and the World. ${ }^{[4]}$ Heidegger uses the concept of Being-in-the-World to explain that every person is always in a context of an objective world and in his own personal subjective world, which can't be separated from him. ${ }^{[10]}$

First, one must consider that the interpretation of the person's experience, means to interpret the person's different ways of existing. ${ }^{[2]}$ And, according to Gelvin, ${ }^{[2]}$ for Heidegger, the best way to describe a person's way of existing is to interpret it's ways of caring or caring-for. For Heidegger, to «carefor» is the most fundamental attitude of the person: we need to care about our own existence to keep living: existing. ${ }^{[2]}$ Although, the «care-for» others is expressed differently than the «care-for» our own. The care-for the other is lived in the form of solicitude, which can be conveyed somewhere between an authentic and preoccupied solicitude or to an inauthentic solicitude: as deep indifference. ${ }^{[11]}$ So, in order to recognize the other's unique existential experience, the person «caring-for», as professional nurse, must share an authentic, preoccupied solicitude, for the «cared-for»- the patient.

This brings us to explain the first component of Being-in-theWorld: the Being-in. Being-in is fundamental to understand, to relate to or to care about the things that surrounds us. ${ }^{[2,8]}$ Because the person exist «in», it is ineluctably affected by his surroundings; «the environment». ${ }^{[2]}$ Lamarre ${ }^{[4]}$ adds that a person is born into a world already there and the person is understood only in and through its relationship with the world, the other and itself.

As for the World - the second component of the Being-in-theWorld: it is more than simply the objective/external/material 
world. ${ }^{[6]}$ According to Lamarre's interpretation of Heidegger, the World is where the person's daily experiences take place and it delineates most of which the person perceives and interprets. When considering the World, it means reflecting on more than the objects of the world surrounding us or the simple environment (Umwelt) ${ }^{[6]}$ it implies reflecting on the world that is shared with other persons (Mitwelt). ${ }^{[6]}$ The Umwelt refers essentially to the world of things, of the nature and of physiological needs; it is the surrounding world of the person. Whereas the Mitwelt refers to the world shared with other persons, that is to say the common world where we interact and coexist with other persons. ${ }^{[4]}$

In another manner, according to Gelven ${ }^{[2]}$ hermeneutics comes from the Greek verb to interpret. For Heidegger, our understanding is never complete without interpretation. Therefore, for him, phenomenology is an approach that allows the construction of the meaning of the various ways we exist to be made explicit without overlooking the way these meanings manifest themselves to us in our everyday lives. In other words, phenomenology is a method that prevents the phenomenologist from taking the things/realities or phenomenon merely as they come to him. Heidegger ${ }^{[6]}$ is faithful to his two principles: a) let the facts speak for themselves and $b$ ) there are no such things as bare, misinterpreted facts. In simple words, hermeneutics is a method to access and eventually explain some of our everyday existence as a human being, by interpreting the facts that are revealed to us. Smythe et al. ${ }^{[12]}$ mention that the phenomenon under study needs to be interpreted considering the particularities of the context of the world where people find themselves. So, HHP values the context where the phenomenon takes place, because that is where the meaning is grounded. They add that when using hermeneutic investigation, it is important to stay immersed in the data and to let the data speak to us.

\section{BRIEF REVIEW OF NURSING LITERATURE}

As mentioned previously, hermeneutic phenomenology is gaining importance in nursing, since it provides an opportunity to better understand the meaning of the lived experience of divers actors. Indeed, using this methodology is pertinent to nursing because, as its holistic approach, it upholds that all individuals are unique and have their own life story. ${ }^{[9]}$ Much research has been published in nursing literature using Heidegger's hermeneutic phenomenology, but only one study has been interested in the cared-for with children/patients living with disabilities. ${ }^{[13]}$ So considering the lack of knowledge in this field of epistemology and nursing practice, we hope to make HHP more appealing to nursing researchers who are interested in constructing knowledge of the lived experience of the cared-for with disabilities.
Newman, Cashin and Waters ${ }^{[13]}$ argue that to ensure the accuracy of HHP with individuals who are living with autism, it is important to slightly modify the research methodology. Because of their impaired cognitive ability, the authors question the plausibility of the individuals living with autism to express the meaning of their lived experiences. Thus, they suggest the use of concrete telling as a method of collecting qualitative date to help them communicate their lived experiences. However, because individuals with autism may have more difficulty expressing their concrete lived experiences through language, they recommend the use of visual cues of a particular experience, such as diary and drawing. These visual cues will then enable the individual to tap into eidetic memory and then help him describe the particular experience. The researcher will then be able to interpret this material and develop an understanding of the individual way of being-in-the-world.

\section{THEORETICAL ISSUES USING HHP WITH THE Cared-for}

This section discusses the theoretical issues of using HHP with cared patients in the nursing domain. It is in turning to the concepts of fore-structure and situatedness of the researchers as well as the notion of meaning and Heidegger's theory of truth, that we are able to explain what can be achieved - as interpretation and knowledge - with HHP inquiries and also what can be challenging in this type of qualitative research project with cared patients.

\subsection{Fore-structure and situatedness of the researchers}

Interpretation is the main key of HHP, so in order to interpret the data, the researchers need to have immersion and familiarity with the phenomenon. This a priori understanding of the phenomenon is called fore-structure. This means that we understand the world with the help of what is already interpreted. The three components of the fore-structure are: fore-having, fore-sight and fore-conception. ${ }^{[2]}$ Because interpretation occurs in relation to what is already known, a fore-having refers to what we know, or our prior awareness of it, before any interpretation. Secondly, a fore-sight is defined as the point of view that we already have, a priori background which allows us to direct our attention to the nursing need for care. For example, it is because of our fore-sight that, in nursing practice, we are able to direct our attention to which action of the care doesn't contribute to well-being of the cared-for. It allows us to focus on the phenomenon. As a result, we do need to have an experience background on the topic of inquiry in order to direct our attention to the need for care. This background is gained from our prior experiences and knowledge working with the cared-for. Thirdly, once we directed our attention to the need for care, the fore-

ISSN 1925-4040 E-ISSN 1925-4059 
conception helps us interpret the phenomenon and make it explicit. The fore-conception is the one attitude by which the phenomenon is interpreted. Since Heidegger highlights the importance of the fore-structure, we, the authors, believe that the background that we already have working with the cared-for is a strength for any nursing research project. Not only it allows us to be made aware of the nature of the phenomenon itself, but it also will help us interpret the meaning of the lived experience of being cared for. The familiarity that we have from working with the cared-for is valued in a HHP research and it allows the researcher to be part of the research. This brings us to elucidate the position of the researchers underpinned in an interpretative paradigm and hermeneutic phenomenology methodology.

According to Lincoln, Lynham and Guba, ${ }^{[14]}$ the interpretivist's aim is to interpret and propose an understanding of what it means to experience a certain phenomenon for the sake of improving nursing practice. In order to bring about this understanding, the phenomenologists need to interpret inter subjectively the perceptions of the participants while always considering iteratively their contexts. Goldkuhl $^{[15]}$ states that the understanding comes from subjective and shared meanings. For Heidegger, the researchers cannot distance themselves from the phenomenon under study. He argued that we cannot study things as they appear to us by distancing ourselves from them. ${ }^{[16]}$ The researchers pre-understanding of a phenomenon is a part of their Beingin-the-world and cannot be bracketed off, since it is part of the world. This is what Heidegger describes as fore-sight, mentioned earlier. Smythe et al. ${ }^{[12]}$ report that Heidegger's hermeneutics of understanding of a phenomenon is already in the world and cannot be separated from their thinking.

Thus, the pre-understanding gained from our experiences and knowledge acquired from working with the cared-for is a positive theoretical aspect of using hermeneutics in this research project. We believe that much can be gained from our experiences working with the cared-for, because it is within our experiences that we are able to disclose understanding of what is brought to us in the world. In other words, because we have an understanding of the cared-for's world, we are able to interpret new facts in relation to what we already know. This helps us get closer to a truth, which we will explain further in this paper. According to Miles et al., ${ }^{[9]}$ accepting the researchers pre-understanding as a part of the interpretation enables researchers to interpret the often taken-for-granted activities and to gain insight into the world.

Interpretation is always based on pre-understanding that is already in the world. As a result, we support that it makes sense to say that it is essential for the researchers to have pre-understanding of the phenomenon of inquiry. It is within these pre-understandings that the researchers are able to modify their understanding of the facts that came to them (forehaving). On the other hand, this pre-understanding can also be seen as a negative theoretical issue, because the meaning attributed to the lived experience of well-being could be influenced by our limited or hermetic pre-understanding of a phenomenon. Therefore, the understandings of a new meaning can vary depending on the pre-understanding - and the ethics - of the researchers studying the phenomenon. In other words: depending on the pre-understanding of the phenomenon that the researchers possess/belief/cherishes, it is possible that the new understanding reveals differences from one researcher to another - foreseeing epistemic relativism. Therefore, because each researcher has different pre-understanding of the phenomenon, they might construct meaning of the lived experience based on false or misinterpreted ground. To conclude this argument, we agree that pre-understanding has positive and negative theoretical issues in a hermeneutic phenomenology. Nonetheless, we believe that much more can be gained than lost using HHP. Therefore, by adding to what is already known or correcting what is already known (pre-understanding), we are ultimately getting closer to a truth that is pursued and contributing to better authentic care.

At last, when reflecting on the researcher's position in a hermeneutic phenomenology, we also wonder if it is even possible to "eliminate" what the researcher knows about the subject of inquiry in any type of qualitative research. Moreover, we can argue that all research projects originate, in part, from a fore-having and fore-sight of the situation. According to Gelven, ${ }^{[2]}$ Heidegger claims that for interpretation to happen something needs to force one to become aware of the as-structure. Let us explain what we mean by this argument. For example, a nurse researcher will come about a topic of inquiry from theoretical or practice experiences. These theoretical or clinical experiences provide her with a priori knowledge that helps her delineate her topic of research, because it makes her aware of the as-structure. Consequently, to be able to outline the research topic, the researchers need to be aware of the phenomenon (fore-sight and fore-having) and have a fore-conception of its meaning. That being said, how can a researcher be aware of what needs to be studied without pre-understanding of the phenomenon? Thus, in respect to Heidegger's philosophy, the process of inquiry of the researcher comes, after all, from the fore-structure of the world. 


\subsection{Meaning and Heidegger's Theory of (a) Truth}

The goal of hermeneutic phenomenology is to access and deliver an interpreted understanding of the meaning individuals give to a phenomenon. Thus, it is important to understand the significance of meaning according to Heidegger. Meaning is what we strive for in hermeneutic research. When conducting a research project with a population of cared-for with disabilities using hermeneutics, the researcher's aim is to interpret the meaning of the cared-for experience. Heidegger believes that hermeneutic inquiry might be used to make explicit the implicit meaning of existential facts. ${ }^{[2]}$ For Heidegger, the meaning needs to be made explicit in terms of its services towards Dasein. ${ }^{[2]}$ Hence, the interpretation needs to be done considering the context of the cared-for, in relation to the Being-in-the-world. Here, Heidegger argues that it is impossible to separate the Being from the World, and this is why he hyphenated Being-in-the-world. ${ }^{[9]}$ This way, using hermeneutics will enable us to gain insight into the cared-for experience by making explicit what it means to experience well-being and the actions of the care.

In Heidegger's major work, Being and Time, he questions the meaning of truth. ${ }^{[2]} \mathrm{He}$ asserts that Truth means disclosure: to expose. Truth comes from the Greek word aletheia, which means unhiddeness. With his analysis of Truth, Heidegger raises two major points. First that truth belongs primordially to the Dasein, and second that the Dasein is both in truth and in untruth. He adds that, "[...] truth is a characteristic of the Dasein coming to be aware of itself through its disclosure of itself in its limitations, possibilities, and tendencies toward concealment [...]". To add to his claim, Heidegger says that the truth does not refer to an external object, but to the Dasein. Therefore, what is then revealed (uncovered) must be a characteristic of the Dasein itself. ${ }^{[2]}$ As a result, the truth doesn't exist independent of the Dasein.

After considering Heidegger's theory of truth, we question certain theoretical aspects of studying the cared-for. Firstly, the notion of unhiddeness makes us wonder what truth can possibly be uncovered in our research project. To be congruent with his theory assertions, we will use the data, such as our observations and verbatim as they are revealed to us by the Dasein (s) - the children, even if we wonder if most of the experience can actually be revealed by the Dasein. We argue that it is not possible that the whole truth might be revealed to the researchers. As a matter of fact, that is what Heidegger meant by Dasein is both in truth and in untruth. Therefore the truth is also part of what's hidden from us, and we can only state that we are getting closer to the meaning of the lived experience of well-being and not the complete meaning of the experience. Secondly, even if everything could be revealed, we argue that it is not possible to grasp all of what is revealed by the Dasein. As mentioned earlier, the researchers must have prior contact with the phenomenon in order to reach an interpretation of the meaning of an experience. We suppose that this pre-understanding could possibly create a shadow on other aspects of the phenomenon that could be discovered. Hermeneutics and HHP, then, are a complex process that demands that the researchers be open to discovering and putting-in-words new meanings. In contrast, we also support that being aware that a Truth is also hidden from us, allow researchers to be more open to discovery of meanings.

To add to the notion of unhiddeness explained above, we are concerned with what can be uncovered when studying the cared-for. With a qualitative research design through a phenomenological hermeneutical approach, it can be made explicit the shared meaning regarding the lived experience of well-being of the cared-for. In doing so, it is important to consider another important theoretical issue of meaning and truth in this field of nursing research. As a result, we are concerned by how much can be uncovered from studying the cared-for. As mentioned above, the Dasein is both in truth and in untruth. This principle makes it already challenging for the researchers to understand the whole meaning of the lived experience of well-being within marginalized groups in an emancipatory perspective.

Finally, as some studies investigate marginalized groups cared-for, uncovering meaning can also be challenging. According to Meleis cited in Rashotte and Jensen, ${ }^{[7]}$ marginalized groups can keep their identities secret and attempt to pass as mainstream. For that reason, it is important for a researcher to establish a trustworthy relationship with a marginalized group. This will help researchers to uncover the experience in its most authentic form. Despite the fact that the cared-for taking part in our research project are in some ways marginalized, we strongly believe that it is less likely that they feel this way in the context of nursing community programs. Our nursing program provides an environment that does not allow marginalization to occur. After all, the program was developed for these children and embodies a vision that supports their blossoming health and well-being. Finally, although we recognize that there are hidden aspects of the phenomenon that we can't discover, we also believe that it is not only a characteristic of studying the cared-for, but also a characteristic of hermeneutic approaches. Let us also remind that the goal of qualitative research is to "produce knowledge grounded in human experience". ${ }^{[17]}$ According to Pesut and Johnson, ${ }^{[18]}$ philosophically influenced investigations such as hermeneutics or HHP aim to interpret meaningful sense of the data by making an effort to stay "true" to the data. Thus, it is already assumed that qualitative research is not used to expose one absolute truth, neither 
to blindly assert that such a concept might or should exists. Nonetheless, what can be learned from qualitative research is indeed greatly important for the nursing practice and discipline.

\subsection{Significance of data}

Another theoretical issue that can emerge from studying the cared-for, is the relevance of the data collected. In this research project, it is the aim to investigate the lived experience of well-being of some children with physical, intellectual or social disabilities. Therefore, we want to ensure that the data collected is relevant enough to enable us to understand the true meaning. Although interviewing the cared-for can be challenging, we believe that they are individuals who are able to report on the meaning of their existence. In fact, in respect to Hedeigger's philosophy, the child or theoretically speaking - the Dasein - is the only one that can make itself accessible to others and describe the meaning of his existence. ${ }^{[4]}$

Being aware of this issue requires us to be adequately prepared before conducting any HHP research project. Finlay and Lyons ${ }^{[19]}$ mention the importance of simplifying the interview questions, making them with small phrases associated with familiar situations for the participants. According to Lloyd, Gatherer and Kalsy, ${ }^{[20]}$ the researcher who is conducting the interview needs to be aware of his or her communication skill and that the way the question is asked is particularly important. In addition, they write that the interview should take place in a location where the cared-for feels safe and that sufficient time must be allocated to enable participants to understand the question and then answer them. In addition, the researcher must have a flexible attitude and the ability to recognize the challenges that participants may face during the interview. Considering this issue, researchers can use diverse approaches such as photovoice as a complementary method of investigating the meaning disclosed in the interviews. This way of approaching the phenomenon is appropriate with the existential values of Heidegger's philosophy that support the experience of well-being for the cared-for with disabilities as subjective and experiential.

\section{ETHICAL ISSUES WHEN DOING HERMENEUTICS WITH CHILDREN LIVING WITH DISABILITIES}

As nurse researchers, we consider it our duty to enquire about the lived experience of children living with physical, intellectual or social disabilities. Too often, these children are left out of research - voice - because of the challenges their disabilities might bring to the research process. Moreover, when we don't consider children living with disabilities in our nursing research program, we lose an opportunity to

Published by Sciedu Press contribute to their well-being by not assessing the reality and need of these children. Consequently, considering the premise that each child is unique, we believe that a qualitative approach to the phenomenon of well-being in children living with disabilities is most appropriate. This section of the paper, focuses primarily on non-normative and normative ethical issues that can be encountered when doing HHP with children living with disabilities, such as the notion of language and the existentials of Being-in-the-world.

\subsection{Notion of language}

We embodied a vision that the cared-for living with disabilities are unique Beings who experience nursing care in their own way and are able to appreciate their life, their existence and their body. Our vision concurs with Heidegger's expression of the Dasein, which states that Dasein is the only one that can make itself accessible to others. ${ }^{[4]}$ That being said, the meaning of well-being for the cared-for living with disabilities is subjective. According to Lamarre, ${ }^{[4]}$ each Dasein has a unique way of being, thinking and understanding his or her surroundings. It is with his or her own understanding of the world that he or she comes to his own unique vision of the world. Because every cared-for is Dasein living in their world and in the world, it is possible to find shared meaning of the lived experience. Having worked with these children for many years, we strongly believe that each child experiences being in a different way. Thus, we believe that the reality for each child is different and is influenced by different ways of Being-in-the-world, but can also have shared meaning from sharing a common world. As Gelvin ${ }^{[2]}$ mentions, the understanding of the meaning of the phenomenon is done with interpretation of the language shared between the child and the researchers.

It is through language that the Dasein makes elicit the facts available to the researchers to interpret. Although we believe that the cared-for with intellectual disabilities are able to understand their world from their unique perspective and somehow express that understanding, we question the ability to accurately only use language to properly inform the researchers on the subject of inquiry. This notion of language highlights one ethical issue that can be encountered using HHP with children living with intellectual disabilities. We are aware that using HHP to understand the meaning of well-being for a child with disabilities can pose challenges. Nonetheless, we also believe that HHP can be a valuable methodology to come to this understanding. Within Heidegger's hermeneutics, we have to consider that the accuracy of the communication between the cared-for and the researchers needs to be based on existential situations and not purely on static language. This means that the interpretation needs to 
be based in the existential phenomenal context of the caredfor and not simply by studying the words from a logical fancy methodology.

Without the context of the situation, the words can be interpreted differently and be assigned an erroneous meaning. Thus, because we have developed rich and insightful knowledge of the existential context of the children with intellectual disabilities, we believe that we are better situated to interpret the meaning of the lived experience being cared for. However, we still need to address the complex and challenging issue of language. To do so, Newman, et al. ${ }^{[13]}$ suggested a modified approach of hermeneutic phenomenology, for example, when studying individuals who have autism. As mentioned in a previous section, when investigating the lived experience of the individuals who have autism, the researchers can help the participant to communicate the experience with concrete illustration of the experience using visual cues, like drawing or a diary. The researcher can then ask them to describe what they have drawn in order to understand the meaning for the participant. As a result, collecting data with interviews and photovoice can be useful and will help counter the limitations of language. Photovoice is described as a method that allows for data collection from the child's perspective. According to Plunkett, Leipert and Ray, ${ }^{[19]}$ the photovoice method requires the participant to take pictures of what is significant for him or her. Indeed, this method provides an opportunity for the cared-for to express the lived experience from their perspective, while adding to the data retrieved from the interviews. These authors claim that meaning is developed through interactions with others, which is indeed congruent with Heidegger's philosophy. Therefore, this method allows for shared meaning of the lived experience. With these methods, we are hoping to understand the cared-for way of Being-in-the-world through this visual and concrete telling (photos). Although one may think that this method does not align with hermeneutic phenomenology, and it is more a way of doing qualitative research like ethnography and case studies, we believe that it is an interpretation of the concrete telling in relation to the Being-in-the-world of the cared-for who keeps it aligned with values underpinned in hermeneutic philosophy and the HHP outlined in this paper.

\section{2 "Existentials"}

Additional issue might arises from our inquiry when studying the cared-for living with social disabilities. As mentioned earlier, it is only in relation to him or herself, the world, and others - that the Dasein is able to interpret the significance of his existence. Because it is fundamental that Dasein relates to others in order to understand his or her existence, we are faced with an issue when studying cared-for who have conditions that make it difficult or impossible to relate to others. Being-in-the world means to exist in - and relate to the world, to others and to oneself. For that reason, the researchers need to interpret the meaning of the phenomenon under study in relation to Being-in-the-world. For example: cared-for living with Asperger is characterized by a socialbehavioral disorder. According to the Fédération Québécoise de l'autisme, ${ }^{[22]}$ a person living with Asperger has altered perception and understanding of human relationships and social rules. That being said, understanding the meaning of the care for the cared-for with Asperger will be challenging. However, we consider it possible to grasp the meaning of the cared-for living experience. Although the cared-for may have some difficulties relating to others, he or she nevertheless exists in relation to the world, the others and the phenomenon. Therefore, an understanding of the lived experience can be gained by considering the Being-in-the-world existential structure. Newman et al. ${ }^{[13]}$ agree that although people living with autism may pose a challenge when participating in a research project, it is still possible that they can explain their experiences by means other than simple words. Indeed, when researchers use hermeneutics for achieving the epistemological goal, they need to interpret the human existence in relation to the structure of Being-in-the-world. It is with the help of the existentials that the researchers are able to understand and interpret the human phenomenon. The three main existentials are: spatiality, corporeality, and temporality. ${ }^{[4]}$ The temporality of the human being: it represents the influence of the past and the anticipation of the future on his or her existence. ${ }^{[4]}$ For Heidegger, Dasein's being is in time and all individual are temporally situated in-the-world. ${ }^{[2,10]}$ The word temporality is used to refer to the way the Dasein experiences and lives as, though and in time. ${ }^{[8]}$ Consequently, because time is one of the fundamental structures of human existence, when a researcher uses interpretation to understand a lived experience, he needs to consider the context of time. ${ }^{[10]}$ As mentioned by Miles et al. ${ }^{[9]}$ being in time has an inherent influence on the interpretation. That is to say, that memories of a lived experience can be retrieved and interpreted not only to reveal the nature of being in the past, but also to share what it means in the present and what are the possibilities for the future. As for the spatiality, it represents the space the human being occupies which limits his possibilities. Human being are more than just situated in time, but also in space. According to Miles et al. ${ }^{[9]}$ and Mackey ${ }^{[10]}$ it is important that the lived experience is also interpreted in relation to space. Not in a sense of the space itself, but what the Dasein reveals in that space. Thus, when the context of the experience is modified, the meaning of the lived experience can also change. To ex- 
plain further, according to Mackey, ${ }^{[10]}$ the researcher needs to pay attention to the description of the experience in order to grasp what is experienced in the background of their awareness. When referring to the corporeality, we mean that the body of the Being acts as a medium between the self and the world. Thus, the knowledge that the Being has of the world is mediated through the sensory experiences of his body. ${ }^{[4]}$ This being said, we assume that because the child is a spatial, corporeal and temporal being, it is possible to interpret rich understanding of his or her lived experience of well-being. Lamarre ${ }^{[4]}$ explains that the existentials are markers that help us understand or interpret human phenomena.

\section{IMPLICATION FOR NURSING PRACTICE AND NURSING RESEARCH}

Nurses care for others by preventing disease, promoting and restoring health and well-being. In order to do so, the nursing discipline needs to provide knowledge that can inform nursing practices. In fact, since nurses are constantly called to intervene considering the unique and particular context of each individual, ${ }^{[23]}$ HHP appears to be a valuable choice, as it provides nursing practice with living knowledge. As Benner ${ }^{[24]}$ mentioned, phenomenology allows nurses to direct their attention to the person's experience in relation with others and to understand the meaning of the person's experience. This way of gaining knowledge is very appealing to nursing because in practice, nurses are called to establish a patient nurse relationship in which the client comes with his experience of health and illness. ${ }^{[24]}$

Carper ${ }^{[25]}$ master work suggests four patterns of knowing that delineates the knowledge of the nursing discipline: empirics, ethics, aesthetics, and personal knowing. Following Carper's important and innovative work, a fifth pattern of knowing was developed by Chinn and Kramer: ${ }^{[26]}$ the emancipatory knowing that is closely related to sociopolitical knowing. This pattern of knowing is essential in order to reduce inequality and injustice in sociopolitical institutions. As for Chinn and Kramer, we recognize that hermeneutic research can contribute to the nursing discipline's knowledge by providing lived experience knowledge. Van der Zalm and Bergum ${ }^{[27]}$ also believe that the knowledge gained from phenomenology research can influence our actions toward individuals in a more thoughtful way. Furthermore, in practice, nurses constantly interpretg what is expressed by the individual regarding the lived experience of health, illness and other nursing phenomenon. Interpretation is used to understand the meaning of what is voiced about the lived experiences in each situation. Thus, nursing intervention or praxis is based on interpretation of the individual information. ${ }^{[28]}$
Following Chinn and Kramer's recommendations, we argue that empirical knowledge can be expressed as an interpretation of empirical events or objects that provide understanding. ${ }^{[26]}$ Consequently, the interpretation of meaning revealed from a hermeneutic phenomenology will provide empirical knowledge to the discipline. Secondly, aesthetic knowing is expressed through the actions and attitudes of, and the interaction with nurses. ${ }^{[26]}$ While the nurse is in relation to others, it is essential that she has knowledge that allows her to understand the meaning of each situation. Indeed, hermeneutic phenomenology and HHP strive to do just that: to interpret the meaning and to provide an understanding of a phenomenon. Thirdly, ethical knowing is also valued to guide nursing practice. Chinn and Kramer ${ }^{[26]}$ characterize ethical knowledge as the knowledge that guides the moral action of the nurse. In order to act accordingly, the nurse needs to have knowledge of what is ought to be done. We believe that the meaning of a phenomenon that is revealed using hermeneutics, can provide some knowledge that helps nurses to take the right action. Fourthly, personal knowing is the expression of the genuine Self. We think that the nurse who understands and recognizes the unicity of each individual, just like she is aware of the own authentic Self, will be able to take actions that relate to the authenticity of the other Self. The hermeneutic research can provide the knowledge that is needed to take action, as well as the shared meaning. Last but not least, hermeneutic phenomenology contributes to emancipatory knowing. Like Chinn and Kramer, we assume that hermeneutics are closely related to emancipatory knowledge and praxis. Chinn and Kramer ${ }^{[26]}$ argue that this pattern of knowing is expressed through actions that intend to make a change to benefit all. Considering the lived experience of the child from his or her perspective helps give a voice to those who too often don't have one. As a result, we believe that HHP is in itself emancipatory. As a matter of fact, this type of phenomenology is used to allow the human experience to be expressed and heard, as is. ${ }^{[29]}$ Using hermeneutic phenomenology with children living with disabilities allows researchers to be engaged in praxis because it helps counter the inequities that can surround this population.

As nurse researchers, we value the subjectivity of the individuals as mentioned above. We believe that each individual is able to appreciate his or her life, existence, body and time. Gelvin ${ }^{[2]}$ mentions that, according to Heidegger, it is a unique characteristic of the Dasein to be able to recognize its own complex existence. Therefore, we believe that the cared-for with disabilities is able to consider and to be aware of his or her own lived experiences. Besides, it is now recognized that a limited understanding of their lived experiences makes it difficult to adequately respond 
to their needs. ${ }^{[20]}$ Hence, Heidegger claims that the ability to reflect upon oneself is the most significant function of the human being. ${ }^{[2]}$ Acknowledging Heidegger's philosophy, we recognize that to understand the meaning of the lived experience of well-being, we need to prioritize the unique experiences and subjectivity of the cared-for with disabilities themselves, because they are the ones who can make sense of their existence. Therefore, it is important for the researchers to respect the values and philosophical assumptions that they hold regarding the nature of the world and the human being. In our research project, we refer to an existentialist and emancipatory ontology perspective that is congruent with Heidegger's philosophy.

\section{Conclusion}

The philosophy underpinning Heidegger's hermeneutic phenomenology demonstrates that it is an appropriate epistemic endeavor to gain insight into the lived experience of wellbeing of children living with physical, intellectual or social disabilities. Nonetheless, as we have argued in this paper, it is important when enquiring about the lived experience of children with disabilities to be aware of the theoretical and ethical issues that the researchers and participants may come across. The theoretical discussion outlined in this paper will allow the researchers and practitioners to take adequate measures in order to prevent and deal meaningfully with the possible issues that we may encounter using hermeneutics with this population. The researchers have a critical responsibility when interpreting the meaning of the lived experience. In order to be congruent with Heidegger's philosophy, the researchers have the responsibility to interpret the meaning of the lived experience by considering Being-in-the-world as the only way of existing. It is through language that meaning can be made available to the researchers to interpret. When interpreting this meaning, the researchers need to stay close to the subjective data disclosed during the interview and never lose sight of the context in which it was communicated. It's by eliciting this shared meaning that we understand the lived phenomenon and contribute most effectively to the nursing discipline.

\section{Conflicts of Interest Disclosure}

The authors declare that there is no conflict of interest.

\section{REFERENCES}

[1] Wilson A. Being a practitioner: an application of Heidegger's phenomenology. Nurse Researcher. 2014; 21(6): 28-33.

[2] Gelvin M. A Commentary on Heidegger's "Being and Time". NewYork: Harper \& Row Publishers Inc; 1970. 233 p.

[3] Ihde D. Language and two phenomenologies. Southern Journal of Philosophy. 1970; 8(2): 399-407. https://doi.org/10.1111/j. 2041-6962.1970.tb02126.x

[4] Lamarre AM. Étude de l'expérience de la première année d'enseignement au primaire dans une perspective phénomonologicoherméneutique. Recherche Qualitative. 2004; 24: 19-56.

[5] Meleis AI. Theoretical nursing: development and progress. 5th edition. Philadelphia: Lippincott, Williams \& Wilkins; 2012. 672p.

[6] Palmer RE. Hermeneutics: Interpretation theory in Schleiermacher, Dilthey, Heidegger, and Gadamer. Evanston: Northwestern University Press; 1969. 283 p.

[7] Rashotte J, Jensen L. Validity in hermeneutic phenomenological inquiry: Towards an ethics of evaluation. Canadian Journal of Nursing Research. 2007; 39(4): 94-115.

[8] Watts M. The philosophy of Heidegger. Montreal \& Kingston: McGill-Queen's University Press; 2011. 300 p.

[9] Miles M, Francis K, Chapman Y, et al. Hermeneutic phenomenology: A methodology of choice for midwives. International Journal of Nursing Practice. 2013; 19(4): 409-414. http://doi .org/10.1 111/ijn. 12082

[10] Makay S. Phenomenological nursing research: methodological insights derived from Heidegger's interpretive phenomenology. International Journal of Nursing Studies. 2005; 42(2): 179186. http://doi.org.acces.bibl.ulaval.ca/10.1016/j.i jnurstu.2004.06.011
[11] Babich B. "On the analytic-continental divide in philosophy: Nietzsche's truth, Heidegger's speaking language, and philosophy" (2003). Articles and Chapters in Academic book collections. Paper 6. Available from: http://fordham.bepress.com/phil_babich/ 6

[12] Smyth EA, Ironside PM, Sims SL, et al. Doing Heideggerian hermeneutic research: A discussion paper. International Journal of Nursing Studies. 2008; 45(9): 1389-1397. http://doi.org/10.1 016/j.ijnurstu.2007.09.005

[13] Newman C, Cashin A, Waters CD. A modified hermeneutic phenomenological approach toward individuals who have autism. Research in Nursing Health. 2010; 33(3): 265-271. http: //doi .org/ 10.1002/nur. 20382

[14] Lincoln YS, Lynham SA, Guba EG. Paradigmatic controversies, contradictions, and emerging confluences, revisited. Chapitre 6 dans Denzin, N.K. \& Lincoln, Y.A. (2011). The SAGE handbook of Qualitative Research. 4th edition. Los Angeles: SAGE publications; 2011. $755 \mathrm{p}$.

[15] Goldkuhl G. Pragmatism vs interpretivism in qualitative information systems research. European Journal of Information System. 2012; 21(2): 135-146. https://doi.org/10.1057/ejis. 2011.54

[16] Sloan A, Bowe B. Phenomenology and hermeneutic phenomenology: the philosophy, the methodologies, and using hermeneutic phenomenology to investigate lecturers' experiences of curriculum design. Quality \& Quantity. 2014; 48(3): 1291-1303. https : //doi.org/10.1007/s11135-013-9835-3

[17] Sandelowski M. Using qualitative research. Qualitative Health Research. 2004; 14(10): 1366-1386. PMid:15538005 https://doi. org/10.1177/1049732304269672 
[18] Pesut B, Johnson J. Reinstating the "Queen": understanding philosophical inquiry in nursing. Journal of Advanced Nursing. 2007; 61(1): 115-121. PMid:18173738 https://doi.org/10.1111/j. 1365-2648.2007.04493.x

[19] Finlay WML, Lyons E. Acquiescence in interviews with people who have mental retardation. Mental Retardation. 2002; 40(1): 1429. https://doi.org/10.1352/0047-6765(2002) 040<0014: AIIWPW $>2.0 . \mathrm{CO} ; 2$

[20] Lloyd V, Gatherer A, Kalsy S. Conducting qualitative interview research with people with expressive language difficulties. Qualitative Health Research. 2006; 16(10): 1386-1404. PMid:17079800 https://doi .org/10.1177/1049732306293846

[21] Plunkett R, Leipert BD, Ray SL. Unspoken phenomena: using the photovoice method to enrich phenomenological inquiry. Nursing Inquiry. 2013; 20(2): 156-164. PMid:22381071 https://doi.org/ $10.1111 / j .1440-1800.2012 .00594 . x$

[22] FQA: Le syndrome d'Asperger [Internet]. Fédération Québécoise de l'autisme: Québec; Available from: http://www.autisme.qc.c a/documentation/nouvelles-recentes-et-archives/le s-ted-definition-du-dsm-iv/syndrome-asperger.html

[23] Watson J. Le caring: Philosophie et science des soins infirmiers. Colorado, Colorado: University Press of Colorado; 1998.317 p.

[24] Benner P. Quality of life: a phenomenological perspective on explanation, prediction, and understanding in nursing science. Advances in Nursing Science. 1985; 8(1): 1-14. https://doi.org/10. 109 7/00012272-198510000-00004

[25] Carper BA. Fundamental patterns of knowing in nursing. Advances in Nursing Science. 1978; 1(1): 13-23. https://doi .org/10.109 7/00012272-197810000-00004

[26] Chinn PL, Kramer, MK. Knowledge development in nursing: Theory and process. 9th edition. St-Louis: Elsevier Mosby; 2015. 274 p.

[27] Van der Zalm J, Bergum V. Hermeneutic-phenomenology: providing living knowledge for nursing practice. Journal of Advanced Nursing. 2000; 31(1): 211-218. https://doi .org/10.1046/j.1365-264 $8.2000 .01244 . \mathrm{x}$

[28] Charalambous A. Interpreting patiens as a means of clinical practice: Introducing nursing hermeneutics. International Journal of Nursing Studies. 2010; 47(10): 1283-1291. http://doi.org/10.1016/j. ijnurstu.2010.02.011

[29] Jardine DW. Awakening from Descartes' Nightmare: On the love of ambiguity in phenomenological approaches to education. Studies in Philosophy and Education. 1990; 10(3): 211-232. https: //doi.org/10.1007/BF00367745

[30] Johnson JL. Philosophical contributions to nursing ethics. Chap. 3 Dans Storch J. Rodney P. Starzomski, R. Toward a moral horizon. Pearson Prentice Hall: Toronto; 2004. 575 p. 